\title{
IMPACTOS DO PIBID ACERCA DO ENSINO POR INVESTIGAÇÃO NA VISÃO DOS PROFESSORES SUPERVISORES
}

\section{IMPACTS OF THE PIBID ABOUT THE TEACHING BY INVESTIGATION IN VISION}

THE SUPERVISORS TEACHERS

\author{
Mariana Bolake Cavalli ${ }^{1}$ \\ Daniela Frigo Ferraz ${ }^{2}$
}

\section{Resumo}

Essa é uma pesquisa acerca dos impactos do PIBID (Programa Institucional de bolsas de Iniciação a Docência) no subprojeto "Ensino de Ciências e Biologia por Investigação: uma relação entre teoria e prática" o qual fora desenvolvido no curso de Ciências Biológicas modalidade Licenciatura da Universidade Estadual do Oeste do Paraná. Após a implementação de um módulo didático com enfoque teórico-metodológico baseado no Ensino por Investigação na sala de aula, realizou-se uma análise qualitativa tendo como instrumento de coleta de dados entrevistas, feitas com os professores supervisores, podendo avaliar que impactos o PIBID provocou na prática pedagógica dos professores supervisores, aos alunos das escolas de educação básica e se os professores passaram a utilizar a metodologia abordada em suas aulas. Ficou evidente o aumento do interesse dos alunos pela aula e para os professores supervisores possibilitou uma visão de novas metodologias, ainda que explicitem algumas dificuldades em dar continuidade desse enfoque em suas aulas devido a uma série de fatores, como por exemplo a questão do pouco tempo destinado ao planejamento nas escolas em que trabalham.

Palavras-chave: Ensino por Investigação. Professor Supervisor. Educação Básica.

\begin{abstract}
This is a research about the impacts of PIBID (Program Institutional Scholarship Initiation to Teaching) on the subproject "The Teachings of Sciences and Biology by investigation: a relationship between theory and practice" which was developed by the biology science graduation course, license module of State University of West Paraná. After the implementation of a didactic module with theorical-methodologic focus based on investigation teaching in the classroom, a quality analysis was made having as instrument of data collection interviews, done with the supervisors teachers, being able to evaluate what impacts the PIBID done in their pedagogic practice, to the basic education schools students and if the teachers started to use the methodologic approached in their classes. It became evident the raise of interest of the students for the lectures and for the supervisors teachers made possible a vision of new methodologies, although there is a few difficulties in keep the

\footnotetext{
${ }^{1}$ A autora possui Mestrado em Educação na UNIOESTE. Participa do Grupo de Pesquisa em Epistemologia da Biologia- GEBCA, vinculado ao Grupo de Pesquisa em Educação em Ciências e Biologia- GECIBIO pela Universidade Estadual do Oeste do Paraná. E-mail: marianabolake33@ @otmail.com

${ }^{2}$ A autora é professora Assistente do curso de Ciências Biológicas da Universidade Estadual do Oeste do Paraná. Tem experiência na área de Educação em ciências atuando principalmente nas seguintes linhas de pesquisa: Educação em Ciências, Ensino de Biologia, Formação de Professores. É membro da ABRAPEC (Associação Nacional de Pesquisadores em Educação em Ciências) e membro do GECIBIO (Grupo de Pesquisa em Educação em Ciências e Biologia) junto ao CNPq. E-mail: dfrigoferraz@gmail.com
} 
focus in their classes due a series of factors like the short period of time destined to planning in school which they work.

Keywords: Education for Investigation. Supervisor Teacher. Basic Education.

\section{INTRODUÇÃO}

O subprojeto do Programa Institucional de Bolsas de Iniciação à Docência (PIBID), do curso de Ciências Biológicas - Licenciatura, intitulado: Ensino de ciências e biologia por investigação: uma relação entre teoria e prática, desenvolveu-se desde o ano de 2010 até o ano de 2013 na Universidade Estadual do Oeste do Paraná- UNIOESTE, adotando como enfoque teórico e metodológico o Ensino por Investigação (EPI).

Segundo Carvalho (2010) o Ensino por Investigação parte do pressuposto de que é necessário mudar o foco da dinâmica da aula, deixando de ser uma mera transmissão do conteúdo, conseguindo com isso conquistar o interesse do aluno pela aula. Para isso acontecer é necessário rever novas estratégias metodológicas para serem utilizadas em sala de aula, pois o professor ao assumir o papel de mediador do processo de aprendizagem deverá acompanhar as discussões, provocar novas questões para que aconteça a construção dos conceitos científicos e contrapor as ideias que os estudantes têm do seu cotidiano com as teorias científicas. Schnetzler e Aragão (1995) afirmam que, o professor precisa saber identificar as concepções prévias de seus alunos sobre o fenômeno ou o conceito em estudo. Em função dessas concepções, é preciso planejar, desenvolver e avaliar os procedimentos de ensino para que venham promover a evolução conceitual nos alunos em direção às ideias cientificamente aceitas, como cita Carvalho (2010).

No subprojeto: Ensino de ciências e biologia por investigação: uma relação entre teoria e prática, as atividades desenvolvidas nas escolas participantes foram planejadas e implementadas por meio de módulos didáticos de acordo com o EPI que proporciona o enfoque investigativo. No trabalho aqui apresentado mostra-se às contribuições do subprojeto para a prática pedagógica dos professores supervisores, bem como para os alunos da escola na visão dos mesmos. Além disso, apresenta-se quais as expectativas dos professores supervisores ao entrar no PIBID e o quanto o ensino por investigação contribuiu para sua formação continuada e para os alunos da escola. Analisa-se, por fim, as possibilidades e/ou limitações em dar continuidade ao uso do EPI nas atividades desenvolvidas em sala de aula após a finalização do projeto. 


\section{FUNDAMENTAÇÃO TEÓRICA}

\subsection{O Programa Institucional de Bolsas de Iniciação à Docência (PIBID) na Coordenação de Aperfeiçoamento Pessoal de Nível Superior (CAPES) e na UNIOESTE}

Regulamentado em 2007 pela Capes, o PIBID é uma iniciativa para o aperfeiçoamento e a valorização da formação de professores para a educação básica. Segundo Capes (2013) o programa concede bolsas a alunos de licenciatura participantes de projetos de iniciação à docência desenvolvidos por Instituições de Educação Superior (IES) em parceria com escolas de educação básica da rede pública de ensino, também concede bolsas a professores atuantes na rede pública de educação básica e a professores de universidades públicas.

Assim os Pibidianos, termo usado para se referir aos acadêmicos bolsistas do PIBID, têm a oportunidade de manter um contato maior com o ambiente escolar, com os alunos e com os professores das escolas de educação básica a fim de complementar sua formação acadêmica a partir do contexto das escolas, seu futuro campo de atuação profissional.

O PIBID visa incentivar os professores supervisores e Pibidianos a articular um

processo formativo que estimule a relação teórico-prática das atividades desenvolvidas na escola e ao mesmo tempo trazer uma nova expectativa sobre sua formação e o seu trabalho.

Com as bolsas concedidas pelo programa os Pibidianos têm maior tranquilidade em seguir seu curso de licenciatura e atuar nas escolas públicas com maior facilidade, pois, como Francisco Junior e Zibetti (2011) citam, a inserção desses alunos no PIBID garante a ampliação do tempo destinado à formação no contexto escolar e por esse motivo pode ser considerada uma medida contributiva no atual contexto educacional. Ou seja, contribui para manter o Pibidiano em seu curso de licenciatura sem haver desistência e auxiliando o mesmo a ter conhecimento da realidade escolar em toda a sua complexidade e a partir disso buscar por outras formas de intervir nesse espaço.

O PIBID foi institucionalizado oficialmente na Universidade Estadual do Oeste do Paraná em maio de 2010; sendo que na época em que se desenvolveu o projeto institucional, segundo dados da UNIOESTE (2013), contemplava 9 subprojetos, com 116 acadêmicos, 18 professores supervisores, 18 escolas públicas e 9 professores orientadores da Universidade, sendo desenvolvido nas licenciaturas nos câmpus de Cascavel, Toledo, Marechal Cândido Rondon, Foz do Iguaçu e Francisco Beltrão. 
O curso de Ciências Biológicas - Licenciatura da UNIOESTE no campus de Cascavel, contou com 18 bolsistas participantes do subprojeto, que atuaram nas escolas conveniadas, planejando e implementando módulos didáticos e aulas teóricas-práticas com enfoque teórico metodológico baseado no EPI.

Os Pibidianos também tiveram a oportunidade de participar de reuniões semanais junto com seus orientadores e supervisores, que auxiliaram na orientação do trabalho na escola, bem como no estudo e discussão de textos que deram uma base teórica sólida acerca do Ensino de Ciências de modo geral e mais especificamente sobre os pressupostos do Ensino por Investigação.

De outro lado, temos que o retorno do professor supervisor à universidade estimula-o a buscar novos conhecimentos e estratégias e como consequência a escola em que ele está inserido poderá ser beneficiada, pois passa a ter um profissional, detentor de metodologias inovadoras, preocupado em realizar atividades que promovam o aprendizado dos alunos e promovendo, desse modo, um constante processo de formação continuada.

A formação continuada deve estar presente em diferentes etapas e momentos da carreira profissional do professor, já que:

[...] a formação inicial sozinha não dá conta de toda tarefa de formar os professores: é preciso cada vez mais se promover uma formação permanente que não termine com a formação inicial, nos cursos de licenciatura, mas que vá além disso, que prossiga ao longo do desenvolvimento profissional do professor, como formação continuada em serviço. (MODESTO,2002, p.11).

A formação continuada é importante para o professor e é considerada como uma forma de obter qualificação. Segundo Prada (2001), esta qualificação, pelo ponto de vista das pessoas em geral, tem sentido de eficácia e eficiência na formação do trabalhador da educação, quando deveria na realidade visar um desenvolvimento humano profissional e uma interação do docente com a cultura local. No PIBID, têm-se a oportunidade de balizar ações concretas a partir da relação entre conhecimentos da cultura local ao mesmo tempo em que se constroem os conhecimentos teóricos produzidos no contexto acadêmico. O enfoque do ensino por investigação é uma dessas possibilidades.

Na sequência do texto são apresentados os pressupostos desse enfoque no Ensino de Ciências e Biologia e a forma como foi utilizado no subprojeto do Curso de Ciências Biológicas Licenciatura da UNIOESTE. 


\subsection{Alguns Pressupostos do Enfoque do Ensino por Investigação no Ensino de Ciências e Biologia}

Sabe-se que uma das finalidades do sistema educacional é proporcionar aos cidadãos capacidades de aprender, para que sejam aprendizes mais flexíveis, eficazes e autônomos (POZO, 2003). Partindo desta premissa e, na expectativa de reverter os problemas que afligem a educação, acredita-se que a implementação de práticas educativas inovadoras, dentre as quais se destaca o uso de estratégias de ensino diversificadas como o Ensino por Investigação, possa auxiliar na superação dos obstáculos.

Muitas vezes os alunos não aprendem como resolver problemas, apenas memorizam soluções para situações que são apresentadas pelos professores. Isto é consequência de um ensino em que se acredita que o conhecimento pode ser transmitido verbalmente e assimilado pelos alunos. O EPI tenta trazer os problemas do cotidiano do aluno para a sala de aula, para que a partir deste problema ele construa seu conhecimento, e sem que haja uma memorização de uma solução pronta e acabada, mas sim um verdadeiro entendimento sobre o assunto.

A forma como o aluno aprende é muito importante para que ele construa um conhecimento efetivo e por meio de investigação e experimentação é possível o aluno participar de seu processo de aprendizagem, implicando em mobilizá-lo para a solução de um problema e a partir dessa necessidade, produzir seu conhecimento por meio da interação entre pensar, sentir, discutir, explicar, relatar e fazer segundo Carvalho (2010). Delors (1998), sugere a promoção da aprendizagem por toda a vida, a qual contemple a capacidade de resolver problemas e tomar decisões. Para esse autor, o conhecimento deveria ser ensinado de modo a capacitar os alunos a enfrentarem o inesperado e a incerteza.

O aluno também tem que se interessar pelo assunto de forma que se sinta convencido que valerá a pena se envolver na atividade e que ali existe um problema a ser resolvido. Porém, o tipo de atividade apresentada ao aluno é decisivo para que ele sinta a vontade de se empenhar em resolver o problema. Nas palavras de Pozo:

\footnotetext{
Para que se configurem verdadeiros problemas que obriguem o aluno a tomar decisões, planejar e recorrer a sua bagagem de conceitos e procedimentos adquiridos é preciso que as tarefas sejam abertas, diferentes uma das outras, ou seja, imprevisíveis. O problema é sempre uma situação de uma forma surpreendente. (POZO, 1998, p.160).
}

Assim os alunos utilizam tanto seu conhecimento prévio, quanto ao mesmo tempo ocorre aprendizagem de novos, ambos para que se dê a resolução do problema proposto pelo 
professor. Segundo Clement e Terrazzan (2012), a dinâmica de resolução de problemas pode se desenvolver tanto numa atividade didática de problemas de lápis e papel, quanto de uma atividade com uso de experimento, ou ainda, com uma atividade com uso de texto.

O subprojeto PIBID analisado direcionou o professor e o acadêmico para o desenvolvimento de aulas com enfoque no ensino por investigação, mostrando alternativas metodológicas no planejamento dos módulos didáticos que na sequência foram implementados nas escolas participantes do subprojeto. Para tanto, houve inicialmente o estudo e fundamentação em autores que abordam o tema como por exemplo, Clement e Terrazan (2012), Da Cunha Campos e Nigro (1999), Carvalho (2010) e Gil Pérez et al. (1999). Durante as reuniões do subprojeto foi sugerido aos participantes um sequenciamento didático para formular os módulos didáticos com enfoque investigativo, esses passos foram elaborados a partir das etapas apresentadas por Clement e Terrazzan (2012) e são descritos a seguir.

O primeiro passo é análise qualitativa do problema elaborado pelo professor o qual mostra que, compreender os conceitos, as discussões, as relações científicas, sociais e ambientais envolvidas no fenômeno em estudo. A primeira etapa para um ensino investigativo é conseguir compreender profundamente o fenômeno a ser estudado e suas as diferentes nuances. Mediante essa compreensão, elabora-se um problema real que seja motivador para o desenvolvimento investigativo da aprendizagem. O problema real é a parte fundamental dessa metodologia, o restante da metodologia é consequência do posicionamento do professor para levar os alunos a levantar hipóteses, saber questionar, direcionando a discussão, sem dar uma resposta imediata e pronta sobre a mesma.

O segundo passo é a emissão de hipóteses, após formular o problema é importante que haja uma previsão por parte dos Pibidianos das hipóteses que podem ser levantadas pelos alunos em sala de aula, bem como dos materiais que serão necessários para que os alunos desenvolvam suas hipóteses. As hipóteses são levantadas pelos alunos para responder uma questão/problema que se configurou a partir da situação de interesse. O papel do Pibidiano é estimular o levantamento dessas hipóteses, problematizar as ideias colocadas, e, sem dar a resposta, direcionar a coerência de algumas ideias.

O próximo passo é a elaboração de estratégia(s) de resolução no qual se espera que os alunos elaborem diferentes formas de resolução da questão/problema proposta, explicitando os conhecimentos que dispõem. Ao solicitar aos alunos a elaboração de estratégias de resolução, se aposta na aproximação das atividades dos alunos com atividades que os cientistas/pesquisadores realizam em seu trabalho. 
Também é importante a aplicação da(s) estratégia(s) de resolução, esta é a etapa em que se efetua a resolução propriamente dita da situação-problema. A solução é buscada de acordo com a estratégia estabelecida na etapa anterior, chegando-se assim a um "resultado", ou seja, a uma das respostas possíveis para a situação-problema em questão. Seria a etapa do "como os alunos chegaram aquele determinado resultado".

Outro passo é a etapa de análise do(s) resultado(s) que tem por objetivo contrastar e verificar as hipóteses emitidas, permitindo averiguar até que ponto a avaliação qualitativa da situação (origem de todo o desenvolvimento) estava correta e/ou a estratégia seguida era adequada. É a etapa das explicações, os porquês se chegou aquele determinado resultado e suas aproximações às explicações do conceito científico relacionado.

E por fim a elaboração de síntese explicativa do processo de resolução praticado e sinalização de novas situações-problema. Nesta etapa espera-se que os alunos elaborem uma síntese da resolução do problema (o que pode ser feito de forma escrita ou discussões orais, simulando a divulgação que ocorre na comunidade científica mediante artigos e eventos), ou seja, façam uma recapitulação dos aspectos mais importantes da resolução praticada. Também se espera que sinalizem novas situações-problema que possam surgir a partir do estudo investigativo realizado ou que sejam de seu interesse (pode-se inclusive fazer um mini-evento em que os grupos apresentem as estratégias utilizadas para a resolução das questões/problemas). De qualquer forma, sempre deve se ter uma forma de registro dessas etapas, preferencialmente por vídeo e áudio-gravação.

Segundo Carvalho (2010), o professor deve conhecer bem o assunto para poder propor questões que levem o aluno a pensar, deve ter uma atitude ativa e aberta, estar sempre atento às respostas dos alunos, valorizando as respostas certas, questionando as erradas, sem excluir do processo o aluno que errou, e sem achar que a sua resposta é a melhor, nem a única. Notase que é muito importante que o professor saiba o conteúdo de forma aprofundada para melhor direcionar o aluno ao conhecimento. Pois vai ser nesta hora que o professor vai unir o conhecimento científico dele, com o conhecimento prévio do aluno. Assim o professor vai atuar como mediador do processo da construção do conhecimento.

Para que os participantes se apropriassem dessas questões foram realizadas reuniões com os professores orientadores e supervisores e também os acadêmicos participantes do subprojeto, para auxiliar na reflexão e construção de soluções alternativas para utilizar o ensino investigativo em suas aulas. Trabalhando em duplas, elaboraram-se módulos didáticos com enfoque investigativo, que foram implementados aos alunos da educação básica com 
auxílio do professor supervisor. Assim o subprojeto é um incentivo para que professores atuantes na rede pública de ensino continuem estudando para construírem o conhecimento junto com seus alunos.

\section{ASPECTOS METODOLÓGICOS DA INVESTIGAÇÃO}

A presente investigação ocorreu com quatro professores de três escolas púbicas estaduais da educação básica, participantes do subprojeto PIBID: Ensino de Ciências e Biologia por Investigação: uma relação entre teoria e prática. Os professores foram tratados como P1, P2, P3 e P4 para preservar suas identidades durante a apresentação dos dados.

Para realizar a investigação acerca do que foi modificado após a implantação do PIBID na escola e no cotidiano dos professores, foi realizada uma entrevista estruturada, que segundo Ludke e André (1986) é usada quando se visa a obtenção de resultados uniformes entre os entrevistados, permitindo assim uma comparação imediata. O objetivo da entrevista foi coletar dados referentes às contribuições do projeto PIBID na escola, para os alunos da escola e para os professores participantes do projeto. Levantar quais os impactos causados pelo desenvolvimento do subprojeto PIBID nas escolas parceiras, investigar quais as expectativas dos professores supervisores ao entrar no subprojeto, o quanto o PIBID contribuiu para sua formação continuada e a possibilidade e/ou limitação da continuidade do uso do enfoque investigativo em suas aulas.

No tratamento e análise de dados utilizou-se a abordagem qualitativa que conforme Lüdke e André (1986) tem o ambiente natural como fonte direta de dados. Este estudo enfatiza a interpretação das transformações no contexto cotidiano das escolas participantes do projeto e também das pessoas envolvidas neste. Assim foi feita a análise visando compreender o que foi falado na entrevista e o que realmente o entrevistado quis dizer com sua fala. Para melhor conseguir separar os dados e chegar ao resultado esperado, as entrevistas foram áudiogravadas, sendo este um processo de fundamental importância, pois de acordo com Zago (2003), o pesquisador fica livre para conduzir as questões além de favorecer a relação de interlocução. Na sequência as entrevistas foram transcritas literalmente e selecionados os trechos para compor os eixos de análises para responder aos objetivos propostos no trabalho.

A partir das entrevistas foram identificados alguns eixos de análises correspondentes aos objetivos desta pesquisa, destacando as informações sobre: 1) Expectativas do professor supervisor ao entrar no subprojeto do PIBID; 2) Dificuldades da continuidade dos professores 
supervisores utilizarem o enfoque do ensino por investigação nas suas aulas e 3) Contribuições do PIBID para os alunos e professores supervisores.

\section{RESULTADOS E DISCUSSÕES}

\subsection{Expectativas ao entrar no subprojeto do PIBID para o professor supervisor}

A professora P1 afirma: "Na verdade é uma forma de inovar, é um desafio na verdade, o dia a dia com 40 aulas não é possível você planejar uma aula diferente". Verifica-se que a professora se sente sobrecarregada sem tempo de preparar aulas utilizando uma metodologia diferenciada. Ainda em sua fala ela afirma: "muitas vezes você se encontra frustrada em sala de aula não alcança certos objetivos", demonstrando um desabafo quanto a sua frustração por não conseguir atingir determinados objetivos que gostaria de atingir, e deixa a entender que o subprojeto auxilia ao apresentar metodologias alternativas, podendo contribuir para inovar processo de ensino e de aprendizagem. P2 cita em sua fala: "Que houvesse uma transformação dentro da escola nas matérias de ciências e biologia, dentro da minha disciplina" mostra a espera de uma transformação, uma inovação em suas matérias de ciências e biologia, a partir de sua entrada no subprojeto do PIBID.

Verifica-se que o PIBID auxilia na formação continuada dos professores envolvidos, dando um suporte ao professor ao contribuir em suas atividades pedagógicas. Portanto o projeto contribui para poucos professores da rede básica, o que dificulta o acesso a uma formação permanente para os professores. Esse processo é importante já que segundo autores como Modesto (2002) a formação inicial sozinha não dá conta de toda tarefa de formar os professores: é preciso cada vez mais se promover uma formação permanente que não termine com a formação inicial, nos cursos de licenciatura, mas que vá, além disso, que prossiga ao longo do desenvolvimento profissional do professor.

As professoras P3 e P4 tiveram falas semelhantes dizendo: "Aprender de uma maneira diferente dar aula, buscando metodologias diferenciadas e renovando a minha aprendizagem também, acho que essa foi a minha maior expectativa" e "Esperava algo novo, sabia que seria um sistema diferente de ensino, mas não sabia como iria funcionar, eu achei que era uma forma difícil de ser trabalhada até por que eu não conhecia a metodologia investigativa”. Nota-se que as professoras esperavam mudanças, mas não sabiam bem como seria, até que ao participar do projeto perceberam que se tratava do enfoque didático- 
metodológico relativo ao ensino por investigação e passaram a compreender como funcionava este enfoque.

Segundo Candau et al. (1987) a reflexão sobre a didática parte do compromisso com a transformação social, com busca de práticas que tornem o ensino de fato eficiente, rompendo com a prática profissional individualista, promovendo assim o trabalho em comum de professores. Assim as professoras supervisoras têm a possibilidade de trocar experiências entre elas e os Pibidianos, aprimorando sua metodologia.

Visualiza-se, portanto, que para trabalhar no enfoque investigativo, tem que haver uma mudança de atitude na prática pedagógica do professor. O professor vai se tornar um mediador do conhecimento, mais isso não vai diminuir sua importância, e sim aumentar, pois nesse processo vai ter uma função essencial orientando e mediando seus alunos para que aconteça a construção do conhecimento.

\subsection{Dificuldades da continuidade dos professores supervisores utilizarem o enfoque do ensino por investigação nas suas aulas}

As dificuldades de continuidade do enfoque investigativo, na visão de P1 está relacionada com a carga horária destinada para a hora-atividade. Para ela "[...] com 40 horasaula e apenas 10 horas-atividade eu não consigo para cada aula ter essa metodologia, primeiro, existe uma sobrecarga de conteúdo para a quantidade de aulas semanais". Verifica-se que a principal dificuldade relatada é a hora-atividade reduzida ou insuficiente e hora aula também devido a grande quantidade de conteúdos a serem desenvolvidos durante o ano letivo. Segundo Czekalski (2008) a hora-atividade foi implantada devido a excessiva carga horária cumprida pelos docentes, que inviabilizava a prática educativa, principalmente em relação à forma continua de serviço. Porém, ainda é uma luta dos professores da educação básica da rede pública, o aumento da hora-atividade.

Nesse sentido o PIBID pode proporcionar aos professores supervisores uma formação continuada, com novas ideias, metodologias e ampliação de conhecimento através dessa troca de experiências com a equipe do projeto. Segundo Tobaldini (2013) o PIBID representa para o espaço escolar, uma possibilidade de colaborar na formação de professores mais bem qualificados, os quais poderão suprir as necessidades que os alunos da Educação Básica enfrentam no cotidiano, além de propiciar aos profissionais outros questionamentos sobre o fazer docente. 
Nas falas de P2 e P4 nota-se a dificuldade de aplicar todas as aulas no enfoque investigativo: "Não adianta tentar tampar o sol com a peneira e dizer que tudo vai ser ensino por investigação, se fosse trabalhar com o ensino por investigação todo o conteúdo precisaria ter mais 5 aulas semanais para conseguir começar e terminar” disse P2. Já P4 acredita que "Para alguns assuntos é muito interessante, porém no contexto de outros assuntos fica mais difícil ou eu ainda não sei trabalhar, por exemplo, quando você pega o conceito de corpo humano, ai fica difícil fazer uma aula investigativa".

Com essas falas nota-se que os professores sentem muita dificuldade de trabalhar com o ensino investigativo devido a fatores já mencionados anteriormente como a carga horária reduzida e também em alguns conceitos específicos, como o de corpo humano. Nesse sentido, Carvalho e Gil-Pérez (2000) afirmam ser necessário adquirir conhecimentos teóricos sobre aprendizagem das ciências e também saber analisar criticamente o ensino tradicional para auxiliar nas limitações e deficiências da prática pedagógica docente e também para contribuir com futuras mudanças em sala de aula.

É necessário deixar claro que o EPI não possui uma "receita" de como utilizar o enfoque investigativo, mais sim uma "essência" de um ensino diferenciado, para contribuir no ensino-aprendizagem da educação básica. Nota-se que houve uma mudança significativa nas atuações na sala de aula e isso é positivo para a melhoria da prática pedagógica dos professores supervisores.

\subsection{Contribuições do PIBID para os alunos da escola e professores supervisores}

P1 cita a presença dos bolsistas nas salas de aula, como um exemplo aos alunos do colégio "Faz o aluno se sentir mais próximo da universidade tendo esta oportunidade, não é por eles estarem em uma escola pública que vai impedi-los de ter acesso a um ensino superior” e P3 afirma “[...] os alunos se motivaram a estudar mais e pensar em fazer uma faculdade futuramente, sendo que os bolsistas são da UNIOESTE e alguns alunos planejam fazer o vestibular”.

Francisco Junior e Oliveira (2011) relatam que as iniciativas arroladas dentro do PIBID anseiam promover o fortalecimento da integração entre a universidade e a educação básica como uma forma de superação da dicotomia teoria-prática. Pode-se perceber que é muito importante para a escola a presença dos integrantes do PIBID, mesmo que nem todos os 
alunos tenham a oportunidade de participar das aulas, eles percebem a presença dos universitários no colégio e notam a importância de um curso superior.

As professoras P2 e P3 demonstram em suas falas que os alunos da escola, melhoraram seu desempenho, aumentando o interesse no conteúdo e também suas notas. Segundo P2 “[...] aumentou muito as notas dos alunos, com o atendimento individual e clube de ciências os alunos tiveram um grande estimulo e isso contribuiu muito”. Já P3 percebeu que "os alunos estão mais interessados e estão entendendo melhor o conteúdo, fiz um comparativo e a turma que tem o PIBID tem um desempenho melhor do que as outras que não tem, eles participam mais".

Segundo Carvalho (2010) uma atividade investigativa deve levar o aluno a refletir, discutir, explicar e relatar seu trabalho aos colegas. Percebemos que com estas aulas no enfoque investigativo os alunos ficaram mais interessados em participar e assim tiveram um melhor desempenho nas atividades escolares.

Verifica-se também que a contribuição do subprojeto para o professor da educação básica, é de ampliar o seu espaço de formação, uma vez, que com o retorno à Universidade ele se aproxima de novas discussões que podem amparar a sua prática pedagógica em sala de aula. Conforme o relato de P1: "Como disse antes me sinto amparada e também aprendendo pois, na verdade é uma troca de experiências"

Francisco Junior e Zibetti (2011) citam que os professores e estudantes considerem a apropriação de novos conhecimentos, e assim a participação dos bolsistas na escola junto com os professores supervisores torna-se uma troca de experiências. Participando do PIBID os professores supervisores adquirem conhecimento e aprendem novas maneiras de dar aula, melhorando assim sua prática docente.

Modesto (2002) afirma que é preciso cada vez mais promover uma formação permanente que não termine com a formação inicial, e o PIBID funciona para os professores supervisores como uma formação continuada. Assim, os professores e acadêmicos no PIBID compartilham a responsabilidade de aprender e colaborar na construção do conhecimento dos alunos e assim fazer a diferença em sala de aula.

\section{ALGUMAS CONSIDERAÇÕES}

Verifica-se que na situação atual do professor de educação básica, o enfoque investigativo torna-se uma alternativa, pois são destinadas poucas aulas de ciências e biologia 
por semana para os alunos. E também as horas-atividade nem sempre são suficientes para preparar todas as aulas, no enfoque investigativo, dificultando do professor de preparar aulas diferenciadas sempre. Mas tendo esse contato com o EPI é importante para que tenham mais facilidade em criarem aulas diferenciadas.

A partir das falas dos professores supervisores, o PIBID teve um resultado favorável para os alunos da educação básica, pois com o enfoque investigativo as aulas se tornaram mais interessantes para os alunos, fazendo com que eles participassem ativamente da aula. E nas turmas onde foram desenvolvidas aulas pelos Pibidianos, a maioria dos alunos teve um desempenho melhor na matéria, o que causou um acréscimo das notas naquele momento, por mais que se saiba que esse não é o único fator que pode ter contribuído para tal fato.

Do ponto de vista institucional, o PIBID acaba ficando restrito a poucos professores universitários e da educação básica e também a poucos acadêmicos das licenciaturas, pois são poucas as bolsas ofertadas. O apoio da UNIOESTE para o PIBID é limitado, pois o projeto não é regulamentado na instituição, o que causa falta de reconhecimento do PIBID na universidade.

Por fim, conclui-se que o apoio institucional do PIBID aos acadêmicos e professores supervisores é importante por incentivar a docência e dar uma visão diferenciada sobre o ensino. Porém são poucas as bolsas destinadas ao incentivo à docência, o que deve ser reavaliado pela instituição, pois deveria existir um apoio maior às licenciaturas. Em perspectivas futuras, espera-se que o PIBID se consolide entre as licenciaturas, favorecendo a formação acadêmica dos futuros professores.

\section{REFERENCIAS}

CANDAU, V. M. A didática e a formação de educadores - da exaltação à negação: a busca da relevância. In: CANDAU, V. M. (Org.) A Didática em questão. Editora Vozes Ltda. Petrópolis/RJ, $6^{\circ}$ edição, 1987.

CAPES. Coordenação de Aperfeiçoamento de Pessoal de Nivel Superior, 2013. Disponível em: http://www.capes.gov.br/educacao-basica/capespibid. Acesso em 26/03/2013.

CARVALHO, A. M. P. de. Ensino de ciências: unindo a pesquisa e a prática. São Paulo, SP: Cengage Learning Editores, 2010.

CARVALHO, A. M. P.; GIL-PÉREZ, D. Formação de professores de ciências. São Paulo, SP: Cortez, 2000. 
CLEMENT, L.; TERRAZZAN, E. A. Resolução de Problemas de Lápis e Papel numa Abordagem Investigativa. Experiências em Ensino de Ciências, v.7, n 2, p. 98-116, 2012.

CZEKALSKI, R. A. Apropriação da hora atividade como espaço para a formação de professores em serviço: um estudo sobre a organização do trabalho docente em Telêmaco Borba - PR. 2008. 125f. Dissertação (Mestrado em Educação) - Universidade Estadual de Londrina, Londrina, 2008.

DA CUNHA CAMPOS, M. C.; NIGRO, R. G. Didática de ciências: o ensino aprendizagem como investigação. São Paulo, SP: FTD, 1999.

DELORS, J. Educação: um tesouro a descobrir. São Paulo, SP: Cortez, Brasília, DF: MEC, UNESCO, 1998

FRANCISCO JUNIOR, W. E.; OLIVEIRA, A. C. G. PIBID química: ação e pesquisas na Universidade Federal de Rondônia/UNIR. São Carlos, SP: Pedro \& João Editores, 2011.

FRANCISCO JUNIOR, W.E.; ZIBETTI, M.L.T. PIBID: novos ou velhos espaços formativos? Perspectiva para a formação docente em Rondônia e no Brasil. São Carlos, SP: Pedro \& João Editores, 2011.

GIL PÉREZ, D.; FURIÓ MÁS, C.; VALDÉS, P.; SALINAS, J.; MARTÍNEZTORREGROSA, J.; GUISASOLA, J.; GONZÁLEZ, E.; DUMAS-CARRÉ; A.; GOFFARD, M.; PESSOA DE CARVALHO, A. M .Tiene sentido seguir distinguiendo entre aprendizaje de conceptos, resolución de problemas de lápiz y papel de La realización de prácticas de laboratório. Revista Enseñanza de las Ciencias, v.17. n.2. p. 311-320. 1999.

LÜDKE, M.; ANDRÉ, M. E. D. A. Pesquisa em educação: abordagens qualitativas. São Paulo, SP: EPU, 1986.

MODESTO, M. A. Formação continuada de professores de Matemática: compreendendo perspectivas, buscando caminhos. 2002. Tese de Doutorado. Universidade Estadual Paulista.

PRADA, L. E. A. Formação continuada de professores: experiências em alguns países. Revista Online da Bibl. Prof. Joel Martins, Campinas, v.2, n.3, p.97-117. Jun/2001.

POZO, J. I. (org.). A solução de problemas: aprender a resolver, resolver para aprender. Porto Alegre, RS: Artes Médicas, 1998.

POZO, J. I. Aprendizagem de conteúdos e desenvolvimento de capacidades no ensino médio. In: Coll, César et.al. Psicologia da aprendizagem no ensino médio. Rio de Janeiro, RJ: Editora, 2003.

SCHNETZLER, R.P.; ARAGÃO, R.M.R. Importância, sentido e contribuições de pesquisa para o ensino de química. Química nova escola, n.1. 1995.

TOBALDINI, B. G. Os saberes docentes na formação dos professores: o caso do programa de formação institucional de bolsa de iniciação a docência (PIBID) subprojeto química/UFPR 2010/2012. Curitiba, 2013. 
UNIOESTE. PIBID. Plano de trabalho. Projeto vivências e experiências nas escolas: construindo a profissão docente. 2013.

ZAGO, N. A entrevista e seu processo de construção: Reflexões com base na experiência prática de pesquisa. In: ZAGO, N.; CARVALHO, M. P.; TEIXEIRA, R. (Org.). Itinerários de pesquisa: abordagens qualitativas em Sociologia da Educação. Rio de Janeiro, RJ: DP\&A, 2003. 